\section{Arteritis de células gigantes: una causa infrecuente de tos crónica}

\section{Sr. Director:}

Las manifestaciones sistémicas no habituales de la arteritis de células gigantes incluyen las respiratorias, pudiendo ser éstas también secundarias al propio tratamiento y ser el síntoma de inicio, según algunas series, en hasta el $4 \%$ de los casos. Dentro de ellas, la tos crónica, entendida como aquella que persiste durante al menos tres semanas ha sido descrita como síntoma raro, que habitualmente lleva a un retraso en el diagnóstico de la enfermedad y responde muy pronto al tratamiento esteroideo. El mecanismo fisiopatológico no está totalmente aclarado habiéndose propuesto, entre otras hipótesis, la formación de granulomas en la pared bronquial con vasculitis pulmonar, la alveolitis linfocitaria o la vasculitis de la arteria maxilar interna.

Presentamos el caso de un varón de 73 años, con historia laboral de trabajo en planta petroquímica y antecedentes personales de pielonefritis hace 45 años, neumonía hace 5, y cirugía de dos hernias inguinales. Exfumador de unos 20 años/paquete desde hace más de diez años, no refería otros hábitos tóxicos.

Acudió a consulta por presentar desde hacía unos seis meses tos no productiva, sin ritmo circadiano, no acompañada de disnea, dolor torácico ni fiebre, que había sido tratada inicialmente por su médico de Atención Primaria (MAP) con omeprazol 40 $\mathrm{mg}$, con mejoría inicial para luego empeorar de nuevo a pesar de continuar tomándolo. Refería también astenia y pérdida de apetito, y de unos seis kilogramos de peso en los primeros tres meses, manteniéndose luego sin variaciones ponderales. La exploración física era normal. En la analítica inicial destacaba: Gluc: 148; proteínas totales: 6,3; albúmina: 2,3; PCR: 18,9; fibrinógeno: 1.326; hemoglobina: 11,9. La radiografía de tórax no mostró alteraciones parenquimatosas pulmonares, pleurales ni mediastínicas, pero una ecografía abdominal detectó varias lesiones ocupantes de espacio (loes) hepáticas. Con todo esto, se decidió ingresar al paciente por cuadro constitucional acompañado de tos crónica y presencia de loes hepáticas para estudio.

Durante la hospitalización se continuó el estudio analítico, obteniéndose valores normales de TSH, alfa FP, CEA, PSA, sistemático de orina, ANA, ENA e IgE. El proteinograma dio valores ligeramente elevados de alfa1 globulina. Tanto la inmunofijación en suero como la inmunoelectroforesis en orina mostraron una banda monoclonal de precipitación correspondiente a cadenas ligeras kappa. Las pruebas serológicas para VHC, coxiella, CMV y VHS fueron negativas, y de infección pasada frente a VHB y toxoplasma. Las radiografías de senos paranasales fueron normales, así como una espirometría con test de broncodilatación, pese a lo cual se probó con un tratamiento broncodilatador debido a la persistencia de los síntomas y las dificultades para llevar a cabo otras pruebas de función pulmonar que apoyaran o descartaran con mayor seguridad el diagnóstico de asma por no realizarse en nuestro hospital. Una TAC toraco-abdominal destacaba como únicos hallazgos: Elongación del cayado aórtico y dos imágenes hipodensas en el lóbulo hepático izquierdo, probablemente representativas de granulomas o hamartomas benignos. Se realizó una gastroscopia que mostró la presencia de leves ectasias en tercio superior esofágico y una gran hernia de hiato por deslizamiento de unos $8 \mathrm{~cm}$ sin lesiones en saco herniario. Con estos hallazgos, se reforzó el tratamiento antisecretor con omeprazol a dosis altas ( $80 \mathrm{mg} /$ día en dos tomas) sin que tampoco se obtuviera mejoría. Se le propuso al paciente la realización de fibrobroncoscopia que rechazó inicialmente, continuándose el estudio con un ecocardiograma que no mostró alteraciones significativas.

La causa más importante de tos crónica en el adulto es el tabaquismo, y entre los no fumadores las más frecuentes son el sín- drome de goteo postnasal, el asma y el reflujo gastroesofágico $(1,2)$. En cuanto al diagnóstico, el algoritmo más utilizado tal vez sea el propuesto por el American College of Chest Physician que orienta en el estudio de estas tres patologías más frecuentes, además del tabaquismo (3).

La arteritis de células gigantes es una causa poco común de tos crónica (4-7). Se trata de una panarteritis sistémica de carácter granulomatoso descrita en 1890 por Jonathan Hutchinson que afecta a arterias elásticas de gran calibre y musculares de mediano calibre (8). Se manifiesta predominantemente en las arterias del arco aórtico que irrigan específicamente territorios extra-craneales, especialmente en las ramas de la carótida externa (9). Afecta principalmente a personas de raza caucásica con una incidencia aproximada de $17-18$ por 100.000 habitantes y año en mayores de 50 años, y con más frecuencia a mujeres (10). A menudo se asocia a un cuadro de afectación del estado general y dolor en la cintura pelviana y escapular (polimialgia reumática), no estando claro si se trata o no del mismo proceso $(11,12)$. En la actualidad no existe ninguna evidencia clara sobre su etiología.

Sus manifestaciones clínicas son amplias y variadas, y pueden clasificarse en dos grupos:

1. Síntomas locales, secundarios a la inflamación vascular focal (alteraciones visuales, claudicación mandibular, ulceración cutáneo mucosa, cefalea, engrosamiento arterial, dolor local, etc.).

2. Síntomas sistémicos, como mialgias y otros, secundarios a la producción de citocinas (astenia, anorexia, adelgazamiento y fiebre) (13-15). Puede presentarse con manifestaciones pulmonares, como por ejemplo tos seca, que en algunas series llega hasta un $4 \%$ de casos (10).

El diagnóstico debe sospecharse en aquellos pacientes mayores de cincuenta años que presenten un cuadro general como el descrito. Hay datos de laboratorio muy constantes, como son la elevación de la VSG, usualmente por encima de $100 \mathrm{~mm}$ en la primera hora y un elevado nivel de fibrinógeno (16). Otros hallazgos descritos son: un incremento de las alfa y beta globulinas, enzimas de colestasis con bilirrubina y transaminasas normales, sinovitis en grandes articulaciones, esteatosis, granulomas hepáticos y lesiones vasculíticas (17).

La biopsia de la arteria temporal es la prueba que permite la confirmación histopatológica de la enfermedad (18) (Fig. 1). Los hallazgos histopatológicos típicos consistente en una panarteritis granulomatosa con predominio de células mononucleares y presencia de las células gigantes, localizadas principalmente en los

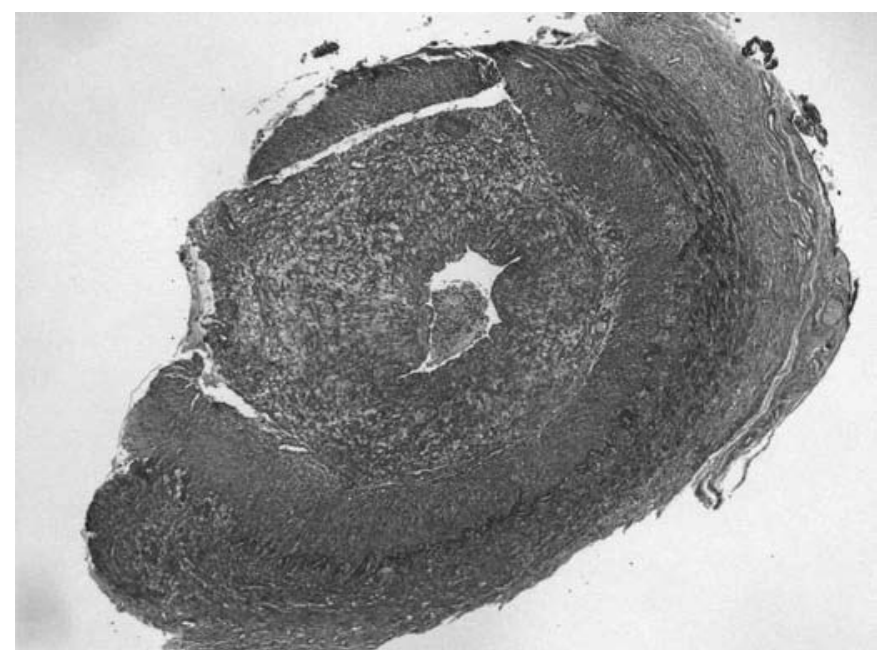

Fig. 1. Biospsia de arteria temporal de nuestro paciente. Corte transversal en el que se aprecia, de fuera hacia dentro, las capas adventicia, muscular y endotelio. Nótese la fila de células gigantes multinucleadas dispuestas por dentro de la capa muscular. Tinción con hematoxilina-eosina. 
alrededores de la membrana elástica interna. Existe destrucción de ésta, ensanchamiento de la capa íntima con estenosis de la luz arterial y ocasionalmente trombosis, presencia de neoangiogénesis y raramente infiltración de polimorfonucleares con necrosis fibrinoide (19).

Debido a la mencionada escasa especificidad de algunos de los datos clínicos y analíticos, The American College of Rheumatology (ACR) definió en 1990 unos criterios para la clasificación de esta enfermedad (20).

El tratamiento de elección lo constituyen los corticoides, que se deben administrar de forma precoz. Con las dosis recomendadas se suele observar una respuesta clínica evidente en las primeras horas, pero es preciso mantenerlas durante 3-4 semanas para luego ir reduciéndolas según el estado clínico y la VSG.

En el caso presentado, nuestro paciente tuvo una forma de presentación atípica de la enfermedad, con ausencia de mialgias y de síntomas locales de la inflamación vascular local, y sólo destacaba la presencia de anorexia y pérdida de peso como síntomas sistémicos comunes. Entre las lesiones atípicas pero asociadas a la enfermedad, presentaba granulomas hepáticos que despistaron el estudio inicial. Descartadas razonablemente las causas más comunes, se consideraron entonces otras más raras de tos crónica y, ante la presencia de un fibrinógeno y VSG persistentemente elevados, aunque la exploración física no apoyaba el diagnóstico y tampoco eran manifiestos los síntomas clásicos, se indicó la realización de una biopsia de arteria temporal que mostró los hallazgos típicos para el diagnóstico de arteritis de células gigantes (Fig. 2).

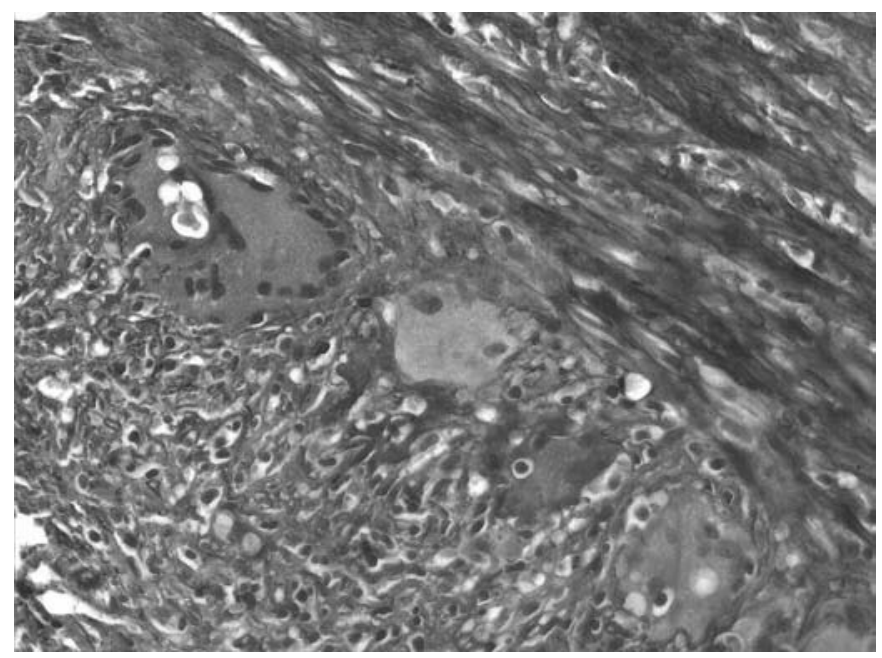

Fig. 2. Detalle del corte anterior a mayor aumento en el que se aprecian con detalle las células gigantes multinucleadas.

Tras el mismo, se inició tratamiento con 60 mg de prednisona/día con llamativa respuesta positiva, desapareciendo la tos, recuperando cifras de hemoglobina en las semanas siguientes y normalizándose los valores de fibrinógeno, VSG y PCR. Como complicación, el paciente desarrolló diabetes esteroidea e hipertrigliceridemia a pesar de la máxima reducción posible de prednisona.

\section{A. Sancho Zamora ${ }^{1}$, L. M. González López ${ }^{2}$, M. A. Martínez García $^{3}$, A. M. Puig Rullán ${ }^{4}$} ${ }_{1,3}^{1,3}$ Servicio de Medicina Interna $y^{2,4}$ Servicio de Anatomía Patoló-
gica. Hospital Santa Bárbara. Puertollano, Ciudad Real

1. De Diego A, Plaza V, Garrigues V, Izquierdo IL, López A, Mullol J, et al. Tos crónica. Arch Bronconeumol 2002; 38: 236-45.

2. Irwin RS, Corrao WM, Pratter MR. Chronic persistent cough in the adult: the spectrum and frequency of causes and succesful outcome of specific therapy. Am Rev Respir Dis 1981; 123: 413-7.

3. Irwin RS, Boulet LP, Cloutier MM, Fuller R, Gold PM, Hoffstein V, et al. Managing cough as a defense mechanism and as a symptom. A consensus panel report of the American College of Chest Physicians. Chest 1998; 114(2): 133-81.

4. Olopade CO, Sekosan M, Scraufnagel DE. Giant cell arteritis manifesting as chronic cough and fever of unknown origin. Mayo Clin Proc 1997; 72: 1048-50.

5. Becourt-Verlomme C, Barouky R, Alexandre C, Gonthier R, Laurent H, Vital Durand D, et al. Symptômes inauguraux de la maladie de Horton sur une série de 260 patients. Rev Méd Interne 2001; 22: 631-7.

6. Joomaye Z, Sotto A, Jourdan J. Isolated prolonged cough caused by Horton's disease. Rev Mal Respir 1997; 14: 59-60.

7. Larson TS, Stephen H, Hepper NGG, et al. Respiratory tract symptoms as a clue to giant cell arteritis. Ann Intern Med 1984; 101: 594-7.

8. Calvo Romero JM. Arteritis de células gigantes. An Med Interna (Madrid) 2002; 19: 257-62.

9. Ruiz Laiglesia FJ, et al. Manifestaciones sistémicas y respuesta al tratamiento en la arteritis temporal. An Med Interna (Madrid) 2003; 20(2): $54-5$.

10. González-Gay MA, García-Porra C. Systemyc vasculitis in adults in northwestern Spain, 1988-1997. Clinical and epidemiologic aspects. Medicine (Baltimore) 1999; 78: 292-308.

11. Salvarani C, Hunder GG. Musculoskeletal manifestations in a population-based cohort of patients with giant cell arteritis. Arthritis Rheum 1999; 42: 1259-66.

12. Hunder GG. Giant-cell arteritis and polymyalgia rheumatica. Med Clin North Am 1997; 81: 195-219.

13. Bustamante Maldonado E, Marí Alfonso B, Monteagudo Jiménez M, Casanovas Martínez A, Jordana Comajuncosa R, Tolosa Vilella C, et al. Análisis de una serie de 55 pacientes con arteritis de células gigantes confirmada por biopsia. An Med Interna (Madrid) 2004; 21: 473-6.

14. Vilalta J, Vilaseca J, Ingelmo M, González L, Tor J, Coca A, et al. Arteritis Temporal. Estudio de 43 casos. Med Clin (Barc) 1982; 78: 307-12.

15. Rivero Puente A, Berasategui Calderón J1, Murie Carrillo de Albornoz JM, Rivero Marcotegui M, García-Bragado Acín F. Arteritis de células gigantes y polimialgia reumática: diagnóstico y evolución de 90 casos. An Med Interna (Madrid) 2001; 18: 191-4.

16. Martínez-Taboada VM, Blanco R, Armona J, Uriarte E, Figueroa M, González-Gay MA, et al. Giant cell arteritis with an erythrocyte sedimentation rate lower than 50. Clin Rheumatol 2000; 19: 73-5.

17. González Camacho L, Sancho Zamora MA, Manzano Espinosa L. Manifestaciones hepáticas de las enfermedades sistémicas. Medicine. Revisiones y actualizaciones: Enfermedades del aparato digestivo 2000; 8(12): 615-20.

18. Evans JM, Hunder GG. Polymyalgia rheumatica and giant cell arteritis. Rheum Dis Clin North Am 2000; 26: 493-515.

19. Casas JM, Acha MV. Revisiones: etiopatogenia de la arteritis de células gigantes. Anales del Sistema Sanitario de Navarra 2003; 21(1): 1184.

20. Hunder GG, Bloch DA, Michel BA, et al. The American College of Rheumatology 1990 criteria for the classification of giant cell arteritis. Arthritis Rheum 1990; 33: 1122-8. 